\title{
Prognostic prediction in acute heart failure patients with extreme BNP values
}

\section{Patrícia Lourenço, Ana Ribeiro, Mariana Pintalhão, Filipe M. Cunha, Joana Pereira, Pedro Marques, João Pedro Vilaça, Marta Amorim, Sérgio Silva \& Paulo Bettencourt}

To cite this article: Patrícia Lourenço, Ana Ribeiro, Mariana Pintalhão, Filipe M. Cunha, Joana Pereira, Pedro Marques, João Pedro Vilaça, Marta Amorim, Sérgio Silva \& Paulo Bettencourt (2017): Prognostic prediction in acute heart failure patients with extreme BNP values, Biomarkers, DOI: 10.1080/1354750X.2017.1289243

To link to this article: http://dx.doi.org/10.1080/1354750X.2017.1289243

Accepted author version posted online: 30

Jan 2017.

Published online: 15 Feb 2017.

Submit your article to this journal $₫$

Џ Article views: 27

Q View related articles ¿

View Crossmark data $[\pi$ 


\title{
Prognostic prediction in acute heart failure patients with extreme BNP values
}

\author{
Patrícia Lourenço ${ }^{a}$, Ana Ribeiro ${ }^{a}$, Mariana Pintalhão ${ }^{a, b}$, Filipe M. Cunha ${ }^{c}$, Joana Pereira ${ }^{a}$, Pedro Marques ${ }^{a}$, \\ João Pedro Vilaça ${ }^{a}$, Marta Amorima ${ }^{a}$, Sérgio Silva ${ }^{a}$ and Paulo Bettencourt ${ }^{a, b}$ \\ ${ }^{a}$ Department of Internal Medicine, Centro Hospitalar São João, Portugal; ${ }^{b}$ Faculdade de Medicina da Universidade do Porto; Unidade I\&D \\ Cardiovascular do Porto, Portugal; ' Department of Endocrinology, Diabetes and Metabolism, Centro Hospitalar São João, Portugal
}

ABSTRACT

Background: Some patients have good prognosis despite elevated B-type natriuretic peptide (BNP), while others have ominous outcome with low BNP. We aimed at characterising these groups of patients.

Methods: We analysed patients prospectively included in an acute HF registry. Vital status within 1-year post discharge was ascertained. A receiver-operating characteristic curve was used to define discharge BNP cut-offs for 1-year death prediction. Among survivors, we compared patients with low and not-low BNP (cut-off $400 \mathrm{pg} / \mathrm{mL}$ ); and among non-survivors those with high vs not-high BNP (cut-off $2000 \mathrm{pg} / \mathrm{mL}$ ). In the specific subgroups of patients with low and high BNP, mortality predictors were assessed with multivariate Cox-regression analysis.

Results: We studied 584 patients, median age 78 years, $62.5 \%$ had HF with reduced ejection fraction; and 199 (34.1\%) died during the first year. Non-survivors were very homogeneous irrespective of BNP, survivors were substantially different. In patients discharged with $B N P<400 \mathrm{pg} / \mathrm{mL}$, increasing age independently predicted death; when BNP $\geq 2000 \mathrm{pg} / \mathrm{mL}$ death predictors were higher NYHA class, and non-use of evidence-based therapy. BNP was outcome associated in both groups.

Conclusions: Different prognostic predictors may play a role in different BNP levels. We suggest that risk stratification in HF would probably be more accurate if made on top of BNP knowledge.
ARTICLE HISTORY

Received 30 October 2016

Revised 12 January 2017

Accepted 23 January 2017

\section{KEYWORDS}

Acute heart failure;

natriuretic peptides; relative insufficiency; prognosis

\section{Introduction}

Natriuretic peptides have known beneficial effects: diuretic, natriuretic, vasodilation, suppression of the renin-angiotensinaldosterone axis and sympathetic tone reduction; they also have anti-fibrotic, and anti-hypertrophic actions (Levin et al. 1998, Kjaer and Hesse 2001, Daniels and Maisel 2007, Calvieri et al. 2012). Increased levels are a hallmark in heart failure (HF), both acute and chronic (Maisel et al. 2002, McGeoch et al. 2002, Tang et al. 2003, Januzzi et al. 2005) Natriuretic peptides are useful for diagnostic purposes and they are also considered the gold standard for prognostic prediction in HF (Berger et al. 2002, Gardner et al. 2003, Januzzi et al. 2006, Latini et al. 2006, van Kimmenade et al. 2006, Masson et al. 2008). Despite their beneficial actions it is recognised that high and increasing natriuretic peptide levels predict worse outcome and that low and decreasing levels associate with better survival. It seems that HF is a state of relative insufficiency of natriuretic peptides since the system is activated but their protective effects are no longer sustained (Cody et al. 1986, Nakamura et al. 1998). This loss of effect does not seem to be observed in all HF patients. Among patients with better outcome in one hand and patients with a more adverse outcome on the other, there is a wide range of possible, and sometimes overlapping, natriuretic peptide levels. Some patients have good prognosis despite elevated B-type natriuretic peptide (BNP) levels and, on the contrary, others have a gloomy outcome with low BNP levels (Miller et al. 2005, Sun et al. 2007).

In order to better understand the apparently paradoxical association of natriuretic peptides with worse outcome we compared patients with different neuro-humoral activation but the same outcome. To comprehend why in some situations this paradoxical association is not maintained we also characterised two well-known groups of patients in clinical practice: HF patients with good prognosis despite high levels of natriuretic peptides and HF patients with ominous outcome despite low natriuretic peptide levels.

Our guiding hypothesis was that in subgroups of patients with extreme (high or low) natriuretic peptide levels, different variables would be outcome associated. Predictors of survival and predictors of death were respectively studied in these subgroups.

\section{Clinical significance}

We characterise two HF subgroups well known in everyday clinical practice: patients that have poor outcome despite 
low natriuretic peptide levels and those with good outcome despite elevated natriuretic peptide levels.

HF patients with low BNP have specific death predictors while those with elevated BNP have different survival predictors. The added knowledge may help physicians that treat HF patients in their daily practice

Our study tries to build knowledge on the natriuretic peptide relative insufficiency phenomenon in HF. Future studies should address mechanisms of natriuretic peptide system resistance and/or relative insufficiency.

\section{Methods}

We analysed patients from a registry of acute HF that was conducted in the Internal Medicine department of São João Hospital Centre, which a tertiary care academic hospital, between January 2009 and December 2010. Physicians treating acute HF patients were aware of the ongoing HF registry. The patients' treatment strategy, timing of discharge and discharge medication were at the discretion of the attending physician. As part of the registry's protocol all patients admitted to our department with the primary diagnosis of acute HF (both de novo and worsening chronic) were eligible for inclusion in the registry. The 2008 European Society of Cardiology guidelines were used for the diagnosis of HF (Dickstein et al. 2008). Both patients with systolic dysfunction and those with HF with preserved ejection fraction were included in the registry.

A complete physical examination at admission and in the discharge day was performed. A 12-lead electrocardiogram was performed at admission. Demographic characteristics, medications in use upon hospitalisation, discharge medication and comorbidities were recorded. All patients were also drawn a venous blood sample within the first $48 \mathrm{~h}$ of hospital admission as well as in the discharge day. BNP determination is a routine laboratory procedure in our hospital; an Abbott $^{\circledR}$ (Lisbon, Portugal) chemiluminescent microparticle immunoassay (two-step immunoassay) is used. The measurement range of this assay is $10-5000 \mathrm{pg} / \mathrm{mL}$. Percentage of BNP variation $(\% \triangle B N P)$ was calculated as: [(admission $\mathrm{BNP}$ - discharge BNP)/admission BNP] $\times 100$. Renal function was assessed using the glomerular filtration rate as estimated by the modification of diet in renal disease (MDRD) formula. An echocardiogram was performed to all patients during hospitalisation; left ventricular ejection fraction $>50 \%$ was considered normal systolic function. Patients' vital status at 12 months was ascertained by consulting hospital registries and by telephone contact with the patients or their relatives.

The registry's protocol conformed to the ethical guidelines of the declaration of Helsinki and it was approved by the local ethics committee. Patients provided informed consent.

A retrospective analysis was conducted in this prospectively recruited patient cohort. Patients with missing data regarding discharge BNP were excluded from the analysis; only a small subgroup of 27 (4.4\%) patients had no BNP measured at discharge. In patients surviving the first year post discharge, those with low $(<400 \mathrm{pg} / \mathrm{mL})$ and not-low $(\geq 400 \mathrm{pg} / \mathrm{mL})$ were compared; and in patients not-surviving this period those with high and not-high BNP (cut-off $2000 \mathrm{pg} / \mathrm{mL}$ ) were also compared. We also studied two specific subgroups: 1) patients with low discharge BNP $(<400 \mathrm{pg} / \mathrm{mL})$; and 2) patients with high discharge BNP $(>2000 \mathrm{pg} / \mathrm{mL})$.

\section{Statistical analysis}

We used a receiver-operating characteristic (ROC) curve to define a discharge BNP cut-off below which there was a high negative predictive value of 1-year death and a discharge BNP cut-off above which there was a reasonably high positive predictive value of 1 year death. Cut-offs chosen was 400 and $2000 \mathrm{pg} / \mathrm{mL}$, respectively.

We first analysed 12-month survivors and non-survivors separately. In the group of survivors those with discharge BNP below and above $400 \mathrm{pg} / \mathrm{mL}$ were compared; and in subset of non-survivors at 12 months those with BNP below and above $2000 \mathrm{pg} / \mathrm{mL}$ were also compared. Chi-square test was used to compare categorical variables and Student's $t$-test to compare continuous variables.

We then studied two specific subgroups: 1) patients with low discharge BNP $(<400 \mathrm{pg} / \mathrm{mL})$; and 2) patients with high discharge BNP (>2000 pg/mL). A Cox regression analysis was used to assess predictors of death in the subgroup of patients with low neuro-humoral activation and to assess predictors of survival in those with high neuro-humoral activation. Multivariate models were built. Variables included in the model were those that differed between survivors and non-survivors in each subgroup.

The $p$ value considered for statistical significance was 0.05 . Data was stored and analysed using SPSS software (IBM Corp, version 20.0, Armonk, NY).

\section{Results}

We studied 584 patients, $45.2 \%$ were male, $62.5 \%$ had HF with reduced ejection fraction and in $41.1 \%$ of the patients the HF was of ischaemic aetiology. Median patients age was 78 years (range from 32 to 100). In a 12-month follow-up period 199 (34.1\%) patients died. Median discharge BNP in survivors was 519.7 (230.6-1034.8) $\mathrm{pg} / \mathrm{mL}$ and in non-survivors was 1233.0 (679.9-2553.0), $p<0.001$. The distribution of death and survival according to BNP categories is depicted in the bar graph of Figure 1.

The area under the ROC curve of discharge BNP for 1-year mortality prediction was 0.75 (0.70-0.79), $p<0.001$. Probability trees for the chosen discharge BNP cut-offs 400 and $2000 \mathrm{pg} / \mathrm{mL}$ are shown in Figure 2. The negative predictive value for 12-month death in patients with discharge BNP $<400 \mathrm{pg} / \mathrm{mL}$ was of $87.3 \%$. The positive predictive value of being dead by 1 year for patients discharged with BNP $\geq 2000 \mathrm{pg} / \mathrm{mL}$ was of $71.6 \%$. As expected, patients had increasingly worse prognosis with progressively higher discharge BNP (data not shown).

Table 1 shows the comparison between patients with low $(<400 \mathrm{pg} / \mathrm{mL})$ and not-low discharge BNP among the 385 1-year survivors. Those with higher discharge BNP were 
predominantly male, older aged, more often had HF with reduced ejection fraction, and they had higher admission BNP. They were also discharged on higher NYHA classes and with lower systolic blood pressure, lower haemoglobin and total cholesterol, as well as with worse renal function. Patients with lower discharge BNP were also less often discharged with beta blocker. Table 1 also shows the comparison between patients with high $(\geq 2000 \mathrm{pg} / \mathrm{mL})$ and not high discharge BNP among the 199 1-year non-survivors. Patients not surviving the first year post discharge were more homogenous irrespective of discharge BNP. They had higher admission BNP, more often had HF with reduced ejection fraction and they were discharged on higher NYHA classes and with worse renal function. In the whole patient population there was a weak negative correlation between BNP and

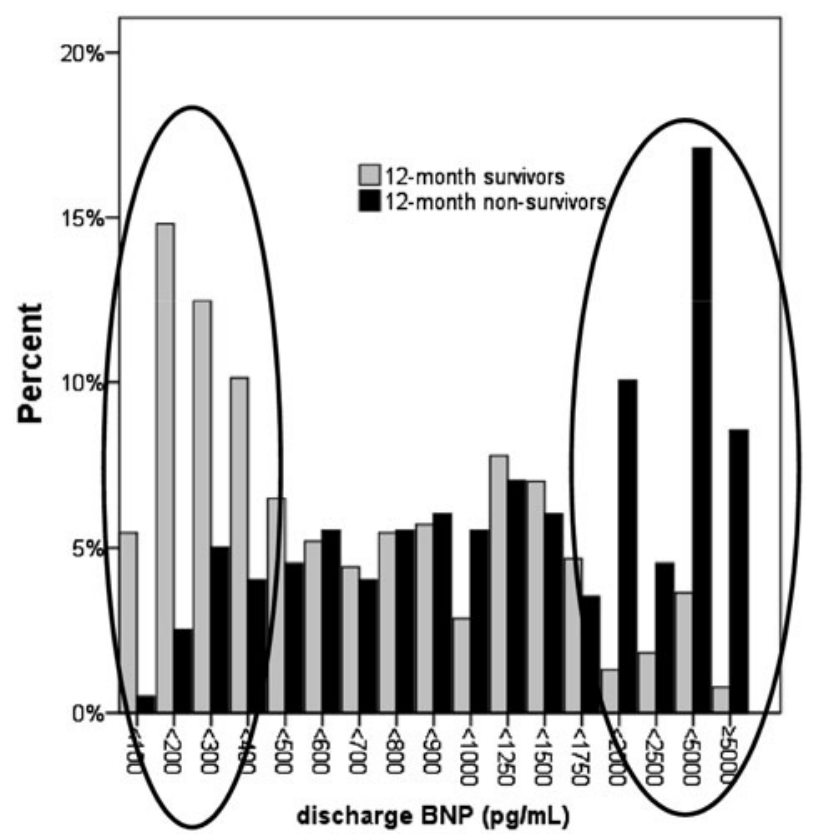

Figure 1. Distribution of death and survival according to BNP categories. Approximately below $400 \mathrm{pg} / \mathrm{mL}$ discharge BNP, there is a clear imbalance favouring survival; and above $2000 \mathrm{pg} / \mathrm{mL}$, there is a strong imbalance favouring mortality.

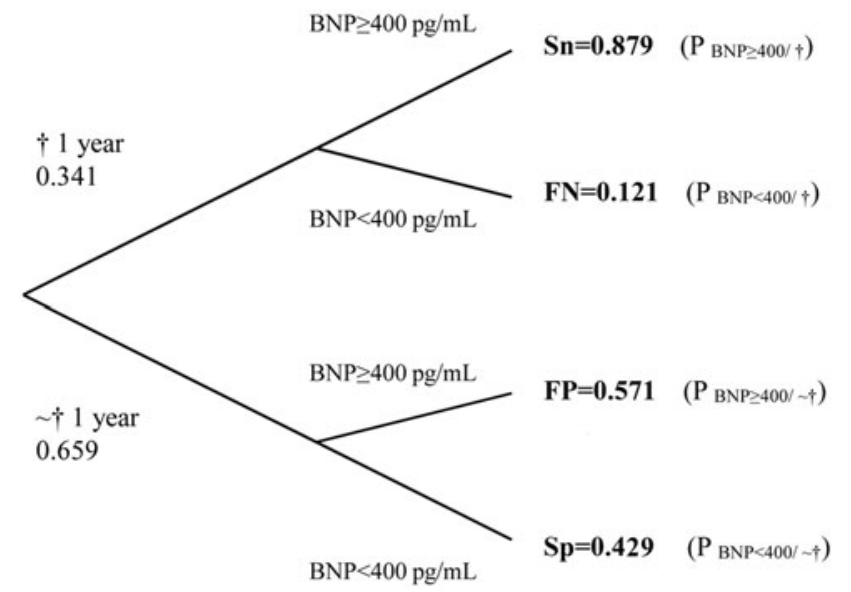

glomerular filtration rate as estimated by the MDRD formula $(p=-0.220, p<0.001)$

We then specifically analysed two subgroups separately: those with low discharge BNP (lower than $400 \mathrm{pg} / \mathrm{mL}$ ) and those with high discharge BNP ( $\geq 2000 \mathrm{pg} / \mathrm{mL})$. One hundred and eighty nine patients (32.4\%) were discharged with BNP lower than $400 \mathrm{pg} / \mathrm{mL}$ : 165 survived a 12-month period and 24 died. Patients discharged with low BNP corresponded to an overall group of younger aged (mean age 74 years vs 77 in those discharged with $>400 \mathrm{pg} / \mathrm{mL}$ ) women $(64.6 \%$ vs $50.1 \%$ in those discharged with higher BNP) with HF with preserved ejection fraction (52.7\% vs $30.1 \%$ ). Table 2 shows their characteristics and compares survivors and non-survivors. Non-survivors were more often older patients with preserved ejection fraction; there was also a non-significant trend towards more women not surviving the first follow-up year. However, the only independent death predictors were age with a HR of 1.05 (95\% Cl 1.00-1.10) per each 1 year increase and discharge BNP with a HR of $1.57(95 \% \mathrm{Cl} 1.00-2.48)$ per each $100 \mathrm{pg} / \mathrm{mL}$ increase. Eighty four patients (14.4\%) were discharged with $\mathrm{BNP} \geq 2000 \mathrm{pg} / \mathrm{mL}: 60$ died during the first year post discharge and 24 survived. Their characteristics and comparison is shown in Table 3. Independent predictors of death were: being discharge in NYHA class $\geq 3$ with a HR of 2.51 (95\% Cl 1.42-4.43) and not under prognostic modifying therapy - those discharged without beta blocker had a HR of death of $1.99(95 \%$ $\mathrm{Cl}$ 1.13-3.52) and those discharged without ACEi or ARB had a HR of death of 2.25 (95\% Cl 1.24-4.08). Higher discharge BNP still predicted death in this high discharge BNP group with a $\mathrm{HR}$ of 1.10 (95\% Cl 1.03-1.19) per each $1000 \mathrm{pg} / \mathrm{mL}$ increase. Importantly, in patients discharged with extreme BNP values no significant differences existed nor in BNP variation during hospitalisation neither in the glomerular filtration rate between 1 year survivors and non-survivors; renal function and BNP change were also not outcome associated in these patient subgroups.

\section{Discussion}

Acute HF patients surviving the first year post discharge were substantially different depending on neuro-humoral

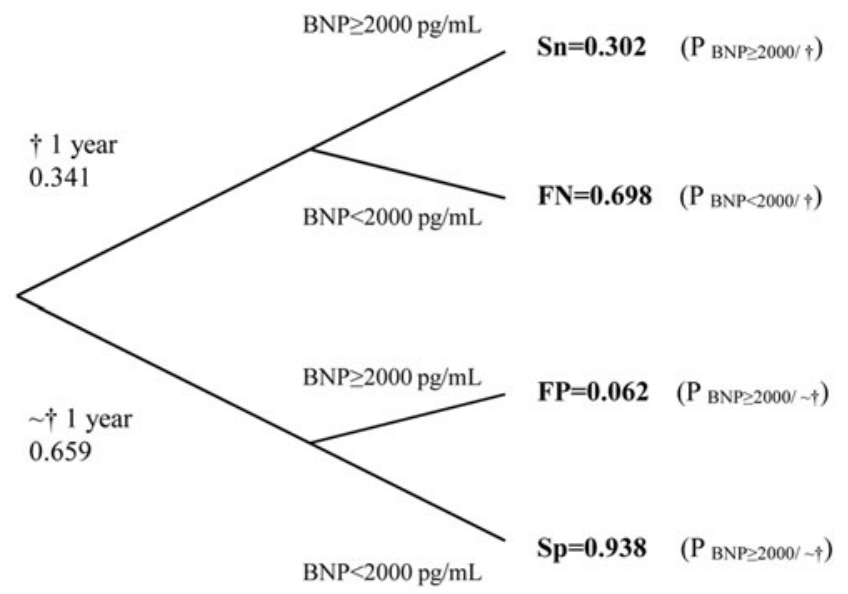

Figure 2. Survival probability trees when BNP cut offs are set at 400 and $2000 \mathrm{pg} / \mathrm{mL}$. †: death; FN: false negative; FP: false positive; P: probability; Sn: sensitivity; Sp: specificity. 


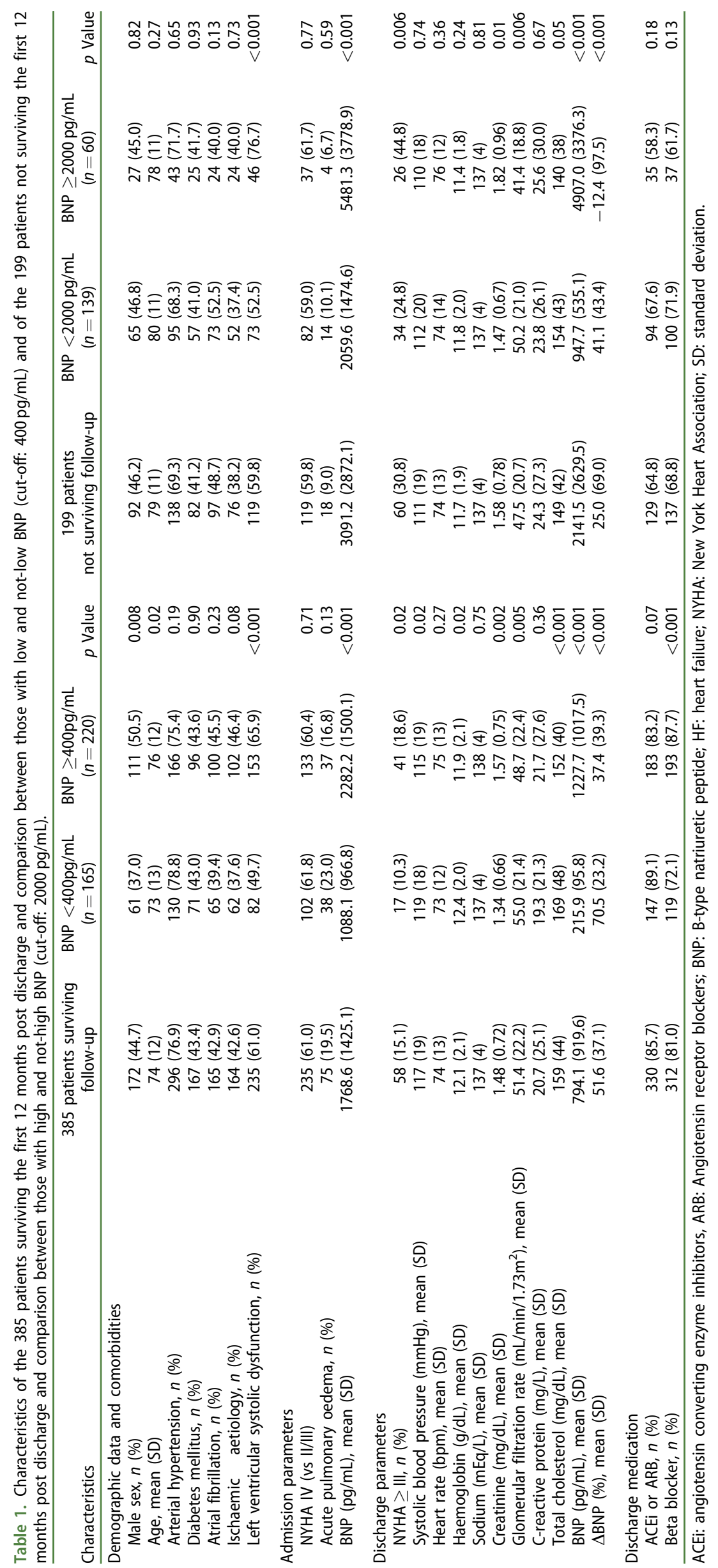


Table 2. Characteristics of 189 patients discharged with BNP $<400 \mathrm{pg} / \mathrm{mL}$ and comparison between 1 year survivors and nonsurvivors.

\begin{tabular}{|c|c|c|c|}
\hline Characteristics & Survivors $(n=165)$ & Non-survivors $(n=24)$ & $p$ \\
\hline \multicolumn{4}{|l|}{ Demographic data and comorbidities } \\
\hline Male sex, $n(\%)$ & $61(37.0)$ & $6(25.0)$ & 0.25 \\
\hline Age, mean (SD) & $73(13)$ & $81(13)$ & 0.003 \\
\hline Arterial hypertension, $n$ (\%) & $130(78.8)$ & $17(70.8)$ & 0.37 \\
\hline Diabetes mellitus, $n(\%)$ & $71(43.0)$ & $10(41.7)$ & 0.90 \\
\hline Atrial fibrillation, n (\%) & $65(39.4)$ & $12(50.0)$ & 0.32 \\
\hline Ischaemic aetiology, $n$ (\%) & $62(37.6)$ & $7(29.2)$ & 0.42 \\
\hline Left ventricular systolic dysfunction, n (\%) & $82(49.7)$ & $5(20.8)$ & 0.008 \\
\hline \multicolumn{4}{|l|}{ Admission parameters } \\
\hline NYHA IV (vs II/III) & $102(61.8)$ & $17(70.8)$ & 0.43 \\
\hline Acute pulmonary oedema, $n(\%)$ & $38(23.0)$ & $3(12.5)$ & 0.30 \\
\hline $\mathrm{BNP}(\mathrm{pg} / \mathrm{mL})$, mean $(\mathrm{SD})$ & $1088.1(966.8)$ & $1272.1(741.5)$ & 0.37 \\
\hline \multicolumn{4}{|l|}{ Discharge parameters } \\
\hline $\mathrm{NYHA} \geq \mathrm{III}, n(\%)$ & $17(10.3)$ & $5(20.8)$ & 0.17 \\
\hline Systolic blood pressure (mmHg), mean (SD) & $119(18)$ & $117(19)$ & 0.56 \\
\hline Heart rate $(\mathrm{bpm})$, mean $(\mathrm{SD})$ & $73(12)$ & $71(12)$ & 0.45 \\
\hline Haemoglobin (g/dL), mean (SD) & $12.4(2.0)$ & $11.8(2.3)$ & 0.16 \\
\hline Sodium (mEq/L), mean (SD) & $137(4)$ & $137(4)$ & 0.74 \\
\hline Creatinine $(\mathrm{mg} / \mathrm{dL})$, mean $(\mathrm{SD})$ & $1.34(0.66)$ & $1.36(0.74)$ & 0.93 \\
\hline Glomerular filtration rate $\left(\mathrm{mL} / \mathrm{min} / 1.73 \mathrm{~m}^{2}\right)$, mean $(\mathrm{SD})$ & $55.0(21.4)$ & $53.4(21.4)$ & 0.72 \\
\hline C-reactive protein (mg/L), mean (SD) & $19.3(21.3)$ & $24.5(31.0)$ & 0.31 \\
\hline Total cholesterol (mg/dL), median (IQR) & $169(48)$ & $166(45)$ & 0.81 \\
\hline BNP (pg/mL), mean (SD) & $215.9(95.8)$ & $259.7(87.4)$ & 0.04 \\
\hline$\triangle \mathrm{BNP}(\%)$, mean (SD) & $70.5(23.2)$ & $71.8(21.4)$ & 0.80 \\
\hline \multicolumn{4}{|l|}{ Discharge medication } \\
\hline ACEi or ARB, $n(\%)$ & $147(89.1)$ & $18(75.0)$ & 0.04 \\
\hline Beta blocker, $n(\%)$ & $119(72.1)$ & $16(66.7)$ & 0.55 \\
\hline
\end{tabular}

ACEi: angiotensin converting enzyme inhibitors, ARB: Angiotensin receptor blockers; BNP: B-type natriuretic peptide; HF: heart failure; NYHA: New York Heart Association; SD: standard deviation.

Table 3. Characteristics of 84 patients discharged with BNP $\geq 2000 \mathrm{pg} / \mathrm{mL}$ and comparison between 1 year survivors and nonsurvivors.

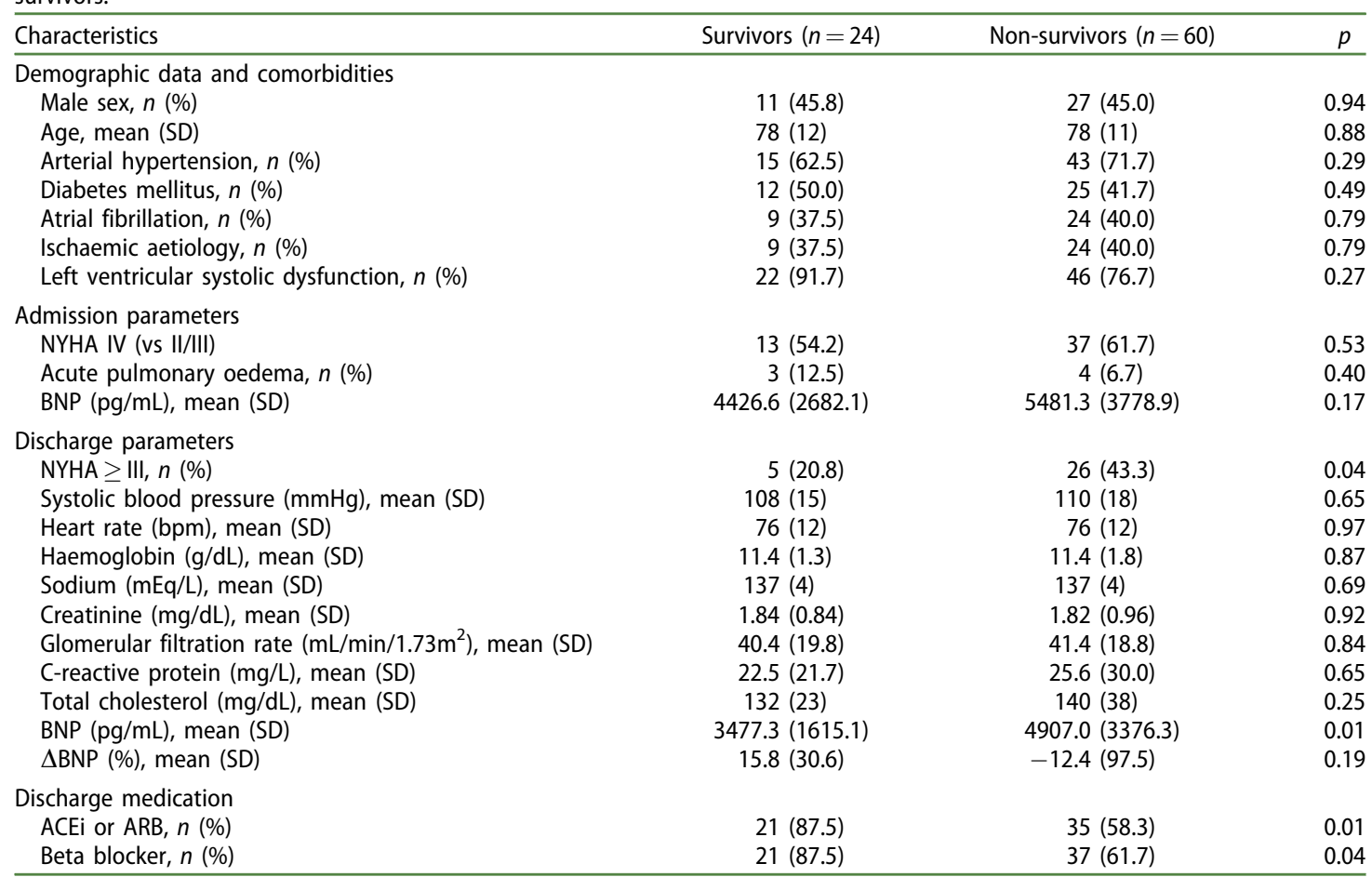

ACEi: angiotensin converting enzyme inhibitors, ARB: Angiotensin receptor blockers; BNP: B-type natriuretic peptide; HF: heart failure; NYHA: New York Heart Association; SD: standard deviation.

activation. Non-survivors were very homogeneous irrespective of discharge BNP. Our results reinforce the importance of natriuretic peptides and their association with outcome more than other proposed variables. As expected, non-survivors had significantly higher BNP than survivors. However, among survivors, patients with higher natriuretic peptide activation differed substantially from those with less activation without outcome differences. This observation is in line with the 
hypothesis that the classically suggested association of many variables with outcome may reflect their association/interaction with the natriuretic peptide system. This hypothesis is further supported by the fact that, among non-survivors, there was a somehow unexpected homogeneity in variables other than the natriuretic peptide system activation.

An unanswered question is the paradoxical association with worse morbidity and mortality along with the activation of a counter-regulatory, "friendly" system like the natriuretic peptide system. Natriuretic peptides are known to play an important role in the regulation of electrolytes and water balance as well as to the regulation and preservation of cardiac hemodynamic and performance (Levin et al. 1998, Kjaer and Hesse 2001, Daniels and Maisel 2007, Calvieri et al. 2012). HF is a condition that presents with natriuretic peptide system activation early in its course and it is increasingly recognised as a state of relative deficiency or response attenuation to natriuretic peptides (Chen 2007). Somewhere in HF progression, natriuretic peptides may 'lose' their effect. Response attenuation has multiple potential contributions: increased natiuretic peptides degradation resulting from clearance receptors or neutral endopeptidase upregulation (Andreassi et al. 2001, Knecht et al. 2002); down-regulation of the natriuretic peptide receptor A (Tsutamoto et al. 1993, Bryan et al. 2007); second messenger - cGMP - response attenuation (Lourenco et al. 2009), alternate processing after secretion and degradation into a multitude of less active forms (Hawkridge et al. 2005, Liang et al. 2007, Martinez-Rumayor et al. 2008). Dipeptidyl-peptidase IV cleaves the functional and active BNP1-32 into the less active BNP3-32 form and has gained increasing attention has part of this alternate processing and inactivation of natriuretic peptides in $\mathrm{HF}$ (Brandt et al. 2006, Lourenco et al. 2013).

Figure 1, that represents the survival and death distributions according to BNP categories, shows that somewhere below $400 \mathrm{pg} / \mathrm{mL}$ there is a clear imbalance favouring survival and that somewhere above $2000 \mathrm{pg} / \mathrm{mL}$ there is also a clear imbalance, this time favouring mortality. These cut offs for survival and death prediction were supported by the ROC curve. As it is shown in the survival probability trees according to these discharge BNP cut offs: the probability of notdying at 1-year once the discharge BNP was $<400 \mathrm{pg} / \mathrm{mL}$ was of $87.3 \%$, and the probability of dying once the patient had a discharge BNP $\geq 2000 \mathrm{pg} / \mathrm{mL}$ was of $71.6 \%$.

One important key to halt HF progression would be to better understand the natriuretic peptides resistance phenomenon. Such resistance or relative natriuretic peptides insufficiency does not appear to be universal in HF since it is recognised that some patients have good outcome despite elevated natriuretic peptide levels. These patients probably represent a group in which natriuretic peptides increase and are still able to perform their beneficial actions. On the other hand, there is a group of patients in which natriuretic peptides response is "blocked" or simply inappropriately not activated and, in this particular group, even low BNP levels associate with ominous outcome.

In the second part of our study we intended to characterise these particular HF patient subgroups (patients discharged with low or very high BNP) in order to better understand the natriuretic peptide system attenuation phenomenon. Our results sustain the hypothesis that in a subgroup of patients in which the natriuretic peptide system is appropriately activated there is some kind of "resistance" to inactivation and they retain their beneficial actions.

HF patients with high BNP that survived the first year post discharge for an acute HF episode were more often in lower NYHA classes $(\leq \mathrm{II})$. Among patients with BNP $\geq 2000 \mathrm{pg} / \mathrm{mL}$, those with better outcome in a multivariate analysis were patients in less symptomatic NYHA classes $(\leq \mathrm{II})$, with a $60 \%$ decrease in the risk of death at 1 year. This suggests that natriuretic peptides maintained their "functionality" and the ability to sustain their diuretic and natriuretic actions keeping HF patients more euvolemic and less symptomatic. In this subgroup of patients, the use of evidence-based therapy also portended a clear survival benefit: those discharged under beta blocker and ACEi or ARB with a 50 and $56 \%$ decrease in the 1-year death risk, respectively. Importantly, in these patients with elevated discharge BNP, 1-year survivors and non-survivors were similar concerning age, major comorbidities, systolic blood pressure and heart rate, and also similar concerning renal impairment. This ultimately means that those patients had no objective reason not to have been discharged on evidence-based therapy; the gap between guidelines and the daily practice is recognised and still an important issue to address in order to improve HF prognosis (de Groote et al. 2007). Higher BNP independently predicted death in this subgroup of high BNP patients - $10 \%$ increase in the 1 year death risk per $1000 \mathrm{pg} / \mathrm{L}$ increase.

In the subgroup of patients that died despite a low discharge BNP, age was an independent mortality predictor per each 1-year increase in age there was a $5 \%$ increased 1-year death risk. The 24 patients that died with a BNP $<400 \mathrm{pg} / \mathrm{mL}$ corresponded to a subgroup of HF patients in which the natriuretic peptide system appears not to have been activated despite need: they had low BNP despite older age, known to be associated with higher BNP levels (Daniels and Maisel 2007). Besides older, non-survivors were also more often women (trend) with preserved ejection fraction; however, none of these latter variables was independently associated with mortality. Effectively, HF patients with reduced and preserved ejection fraction have already been reported to portend a similarly ominous prognosis (Abebe et al. 2016) and women and men have an also comparable gloomy outcome (Fonarow et al. 2009). Higher BNP still independently predicted death in this subgroup of low BNP patients, reinforcing the already known prognostic impact of BNP.

It is interesting to note that, despite the association of higher discharge BNP with worse prognosis even in extremes of natriuretic peptide activation at discharge; BNP changes during hospitalisation did not, as expected (Di Somma et al. 2010), predict outcome; probably, these discharge BNP extremes - low and high - are already a mirror of response and non-response, respectively.

Prognostic modifying therapy appeared to have differential relevance depending on BNP, with utmost importance the higher the BNP. This is a curious, still not that surprising finding. Higher activation of a counter-regulatory system as 
natriuretic peptides may simply reflect an also higher activation of regulatory, vasoconstrictor and anti-natriuretic mechanisms and therefore a more favourable field for prognostic-modifying drugs to show their beneficial effects. Future studies should address mechanisms of natriuretic peptide system relative insufficiency: whether non-activation when needed or inactivation and loss of effect.

The single centre nature of the study poses generalisability concerns. Despite the prospective recruitment of the patients, this specific analysis was retrospective with all its inherent setbacks. Another limitation is the short sample size, particularly in the second part of the study in which we only included the subgroups of patients with low or high discharge BNP. Also important to strain is the fact that the data presented only support associations and not causality or pathophysiological links.

\section{Conclusions}

Different prognostic predictors may play a role in different BNP levels. We reinforce the prognostic importance of BNP even in subgroups of very low or very high BNP; and suggest that risk stratification in HF would probably be more accurate if made on top of BNP knowledge. The use of prognosticmodifying therapy appeared to be of utmost importance the higher the BNP.

\section{Disclosure statement}

The authors report no conflicts of interest

\section{Funding}

This article is a result of the project DOCnet (NORTE-01-0145-FEDER000003), supported by Norte Portugal Regional Operational Programme (NORTE 2020), under the PORTUGAL 2020 Partnership Agreement, through the European Regional Development Fund (ERDF).

\section{References}

Abebe, T. B., et al., 2016. Patients with HFpEF and HFrEF have different clinical characteristics but similar prognosis: a retrospective cohort study. BMC cardiovascular disorders, 16, 232.

Andreassi, M. G., et al., 2001. Up-regulation of 'clearance' receptors in patients with chronic heart failure: a possible explanation for the resistance to biological effects of cardiac natriuretic hormones. European journal of heart failure, 3, 407-414.

Berger, R., et al., 2002. B-type natriuretic peptide predicts sudden death in patients with chronic heart failure. Circulation, 105, 2392-2397.

Brandt, I., et al., 2006. Dipeptidyl-peptidase IV converts intact B-type natriuretic peptide into its des-SerPro form. Clinical chemistry, 52, 82-87.

Bryan, P. M., et al., 2007. Renal hyporesponsiveness to atrial natriuretic peptide in congestive heart failure results from reduced atrial natriuretic peptide receptor concentrations. American journal of physiology renal physiology, 292, F1636-F1644.

Calvieri, C., Rubattu, S., and Volpe, M. 2012. Molecular mechanisms underlying cardiac antihypertrophic and antifibrotic effects of natriuretic peptides. Journal of molecular medicine (Berlin), 90, 5-13.

Chen, H. H. 2007. Heart failure: a state of brain natriuretic peptide deficiency or resistance or both!. Journal of American college of cardiology, 49, 1089-1091.
Cody, R. J., et al., 1986. Atrial natriuretic factor in normal subjects and heart failure patients. Plasma levels and renal, hormonal, and hemodynamic responses to peptide infusion. Journal of clinical investigation, 78, 1362-1374.

Daniels, L. B., and Maisel, A. S. 2007. Natriuretic peptides. Journal of American college of cardiology, 50, 2357-2368.

De Groote, P., et al., 2007. Is the gap between guidelines and clinical practice in heart failure treatment being filled? Insights from the IMPACT RECO survey. European journal of heart failure, 9, 1205-1211.

Di Somma, S., et al., 2010. In-hospital percentage BNP reduction is highly predictive for adverse events in patients admitted for acute heart failure: the Italian RED Study. Critical care, 14, R116.

Dickstein, K., et al., 2008. ESC Guidelines for the diagnosis and treatment of acute and chronic heart failure 2008: the Task Force for the Diagnosis and Treatment of Acute and Chronic Heart Failure 2008 of the European Society of Cardiology. Developed in collaboration with the Heart Failure Association of the ESC (HFA) and endorsed by the European Society of Intensive Care Medicine (ESICM). European heart journal, 29, 2388-2442.

Fonarow, G.C., et al., 2009. Age- and gender-related differences in quality of care and outcomes of patients hospitalized with heart failure (from OPTIMIZE-HF). American journal of cardiology, 104, 107-115.

Gardner, R. S., et al., 2003. N-terminal pro-brain natriuretic peptide. A new gold standard in predicting mortality in patients with advanced heart failure. European heart journal, 24, 1735-1743.

Hawkridge, A. M., et al., 2005. Quantitative mass spectral evidence for the absence of circulating brain natriuretic peptide (BNP-32) in severe human heart failure. Proceedings of the national academy of sciences $U$ $S A, 102,17442-17447$.

Januzzi, J. L. Jr. et al. 2005. The N-terminal Pro-BNP investigation of dyspnea in the emergency department (PRIDE) study. American journal of cardiology, 95, 948-954.

Januzzi, J. L., et al., 2006. NT-proBNP testing for diagnosis and short-term prognosis in acute destabilized heart failure: an international pooled analysis of 1256 patients: the International Collaborative of NT-proBNP Study. European heart journal, 27, 330-337.

Kjaer, A., and Hesse, B. 2001. Heart failure and neuroendocrine activation: diagnostic, prognostic and therapeutic perspectives. Clinical physiology, 21, 661-672.

Knecht, M., et al., 2002. Increased expression of renal neutral endopeptidase in severe heart failure. Life science, 71, 2701-2712.

Latini, R., et al., 2006. Incremental prognostic value of changes in B-type natriuretic peptide in heart failure. American journal of medicine, 119, 70 e23-30.

Levin, E. R., Gardner, D. G., and Samson, W. K. 1998. Natriuretic peptides. New England journal of medicine, 339, 321-328.

Liang, F., et al., 2007. Evidence for functional heterogeneity of circulating B-type natriuretic peptide. Journal of American college of cardiology, 49, 1071-1078.

Lourenco, P., et al., 2009. The cyclic guanosine monophosphate/B-type natriuretic peptide ratio and mortality in advanced heart failure. European journal of heart failure, 11, 185-190.

Lourenco, P., et al., 2013. Dipeptidyl peptidase IV and mortality after an acute heart failure episode. Journal of cardiovascular pharmacology, $62,138-142$.

Maisel, A.S., et al., 2002. Rapid measurement of B-type natriuretic peptide in the emergency diagnosis of heart failure. New England journal of medicine, 347, 161-167.

Martinez-Rumayor, A., et al., 2008. Biology of the natriuretic peptides. American journal of cardiology, 101, 3-8.

Masson, S., et al., 2008. Prognostic value of changes in N-terminal pro-brain natriuretic peptide in Val-HeFT (Valsartan Heart Failure Trial). Journal of American college of cardiology, 52, 997-1003.

Mcgeoch, G., et al., 2002. Plasma brain natriuretic peptide after longterm treatment for heart failure in general practice. European journal of heart failure, 4, 479-483. 
Miller, W. L., et al., 2005. Lower rather than higher levels of B-type natriuretic peptides (NT-pro-BNP and BNP) predict short-term mortality in end-stage heart failure patients treated with nesiritide. American journal of cardiology, 96, 837-841.

Nakamura, M., et al., 1998. Vasodilatory effects of B-type natriuretic peptide are impaired in patients with chronic heart failure. American heart journal, 135, 414-420.

Sun, T., Wang, L., and Zhang, Y. 2007. Prognostic value of B-type natriuretic peptide in patients with chronic and advanced heart failure. Internal medicine journal, 37, 168-171.
Tang, W. H., et al., 2003. Plasma B-type natriuretic peptide levels in ambulatory patients with established chronic symptomatic systolic heart failure. Circulation, 108, 2964-2966.

Tsutamoto, T., et al., 1993. Possibility of downregulation of atrial natriuretic peptide receptor coupled to guanylate cyclase in peripheral vascular beds of patients with chronic severe heart failure. Circulation, 87, 70-75.

Van Kimmenade, R. R., et al., 2006. Usefulness of intermediate amino-terminal pro-brain natriuretic peptide concentrations for diagnosis and prognosis of acute heart failure. American journal of cardiology, 98, 386-390. 